\title{
Analisis dan Perancangan Aplikasi Construction Progress Calculation (CPC) for Piping Discipline Pada PT. IKPT
}

\author{
Siyono $^{l}$, Andi Susilo ${ }^{2}$ \\ Program Studi Teknik Informatika \\ Fakultas Teknologi Informasi, Universitas Respati Indonesia \\ Jl. Bambu Apus I No.3, Bambu Apus, Cipayung - Jakarta Timur 13890 \\ Telp. (021) 8457627, Fax. (021) 84592049 \\ E-mail : yoyon.abc@gmail.com ${ }^{l}$, as.fti.urindo.ac.id ${ }^{2}$
}

\begin{abstract}
The purpose of developing the Construction Progress Planning (CPC) application is to help the piping discipline team to create planning and reporting to determine the progress of ongoing projects. As part of the governance project, each project must be measured its progress throughout the duration of the project. After obtaining the calculation of actual progress, it is then compared with the planned progress for the same period. System development methodologies used in completing the development of the CPC application is Phased Development Model. Phased Development is one approach of RAD (Rapid Application Development) as one of the SDLC. With the CPC application, planning and reporting data processing can be faster and more structured on the ongoing project. Online access facility provides up to date data that can help all interested parties to access the status or condition of the project with a transparent, easy and in real time manner.
\end{abstract}

Keywords: CPC, Piping, Progress, SDLC, RAD, Planning, Project.

\section{PENDAHULUAN}

Sebagai bagian dari tata laksana proyek, setiap proyek harus diukur progress-nya sepanjang durasi proyek tersebut berjalan. Perhitungan aktual progress yang didapat kemudian dibandingkan dengan planning progress untuk periode yang sama. Dari perbandingan antara aktual progress dengan planing progress akan diketahui apakah proyek tersebut dalam kondisi ahead schedule, on schedule ataupun behind schedule.

Pembuatan perencanaan usaha kerja (work Volume) mulai dari proposal hingga eksekusi yang

membutuhkan data dari divisi lain, sering kali terlambat diterima oleh Construction, sehingga mengganggu pekerjaan divisi Construction maupun PT. IKPT secara umum. Salah satu kegunaan datadata tersebut adalah data progress disiplin Piping pada PT. IKPT .

Berdasarkan hasil evaluasi oleh permasalahan terhadap penyusunan progress yang dihadapi disiplin
Piping pada divisi Construction PT. IKPT ini, diusulkan untuk membuat suatu aplikasi yang dapat secara cepat, tepat dan terstruktur untuk menyusun progress disiplin Piping. Aplikasi ini selanjutnya dinamakan Construction Progress Planning (CPC) for Piping Discipline.

Aplikasi Construction Progress Planning (CPC) for Piping Discipline merupakan software yang digunakan oleh tim eksekutor disiplin Piping PT. IKPT untuk melakukan perhitungan progres. Software ini digunakan untuk pembuatan rencana kerja (work volume) mulai dari tahap proposal, yaitu tahap dimana proyek baru dibicarakan, hingga tahap eksekusi yaitu pelaksanaan proyek tersebut. Termasuk di dalamnya adalah tahap perencanaan ulang, yaitu tahap perubahan rencana kerja jika memang perubahan tersebut diperlukan.

\section{LANDASAN TEORI}

Dalam kerangka teori, berisi tentang dasar-dasar teori yang berhubungan dengan analisis dan perancangan aplikasi Construction Progress Calculation (CPC).

\subsection{Piping Engineer}

Piping Engineer menurut Donny Agustinus (2010, p203) mempunyai tugas untuk merancang pengalirkan fluida dari suatu tempat ke tempat yang lainnya. Fluida yang berada di dalamya dapat berupa gas, air, maupun vapour yang mempunyai temperatur tertentu. Karena umumnya material pipa terbuat dari metal, maka sesuai dengan karakteristiknya yaitu jika diberi temperatur atau dialirkan temperatur di dalamnya, maka pipa atau metal tadi akan mengalami pemuaian apabila fluidanya panas dan pengerutan jika fluidanya dingin.

Setiap kejadian pemuaian atau pengerutan dari pipa tadi, akan menimbulkan pertambahan atau pengurangan panjang pipa dari ukuran semula jika diukur dalam skala horisontal. Akibat pergerakan pipa tersebut, maka akan ada gaya yang menekan atau menarik pompa dan tangki disamping juga akan menimbulkan gaya balik terhadap pipa tadi.

Semua perhitungan tersebutlah yang menjadi tugas utama dari seorang Piping Engineer. Dengan 
kata lain, seorang Piping Engineer mempunyai tugas untuk menghitung dan menganalisa suatu sistem pempipaan dalam sebuah Plant sedemikian rupa sehingga sistem Piping dan Plant secara keseluruhan dapat tetap beroperasi secara aman di dalam berbagai kondisi.

\subsection{RAD}

Menurut Alan Denis (2009) RAD adalah sebuah proses pengembangan perangkat lunak sekuensial linier yang menekankan siklus perkembangan yang sangat pendek. Jika kebutuhan dipahami dengan baik, proses RAD memungkinkan tim pengembangan menciptakan "sistem fungsional yang utuh" dalam periode waktu yang sangat pendek (kira-kira 60 sampai 90 hari.

\subsection{PHP}

Menurut Abdul Kadir (2010,p2-p5) PHP (PHP Hypertext Processor) merupakan salah satu bahasa pemrograman berbentuk skrip yang sangat popular dalam pembuatan aplikasi web. PHP tergolong sebagai open source, yang implisit berarti kita bisa menggunakannya tanpa perlu membelinya.

PHP memungkinkan pembangunan halaman web secara dinamis. Hal seperti ini tidak bisa dilakukan hanya dengan menggunakan HTML. Sebagai gambaran, berkas yang hanya berisi kode HTML tidak mendukung pembuatan aplikasi yang menghasilkan dokumen PDF dan tidak bisa berhubungan dengan database.

\section{ANALISIS DAN PERANCANGAN}

Dalam tahap analisis (Analysis) terdapat beberapa tahapan untuk menganalisa aplikasi Construction Progress Calculation (CPC) ini. Tahaptahap tersebut adalah tahap Requirements Determination, tahap Fuctional Modelling, tahap Structural Modelling, dan tahap Behavioral Modelling.

\subsection{Requirements Determination}

Terdapat dua jenis requirements, yaitu nonfunctional requirements dan fuctional requirements. Requirements determination sendiri merupakan laporan langsung berupa teks yang memuat daftar functional dan non-functional requirements secara garis besar. Functional requirements dan nonfunctional requirements aplikasi CPC ini dapat dilihat pada Tabel 3.1.

Tabel 3.1 Requirements Determination Aplikasi CPC

\begin{tabular}{|l|l|l|}
\hline \multicolumn{2}{|c|}{ Requirement Determination } \\
\hline \multicolumn{2}{|c|}{ Functional Requirements } & \multicolumn{1}{|c|}{$\begin{array}{c}\text { Non-Functional } \\
\text { Requirements }\end{array}$} \\
\hline 1 & Recording Data & Usability, Kemudahan \\
& - Menyimpan data & menggunakan aplikasi \\
& Planning, Eksekusi, & \\
& FWC, dan data progress. & \\
& - Menyimpan historical & \\
& data. & \\
& - Menyimpan revisi data. & \\
\hline
\end{tabular}

\begin{tabular}{|c|l|l|}
\hline 2 & $\begin{array}{l}\text { Fungsi Work Volume } \\
\text { Aproval }\end{array}$ & $\begin{array}{l}\text { Reliability, kehandalan } \\
\text { dan Keamanan aplikasi. }\end{array}$ \\
\hline 3 & $\begin{array}{l}\text { Akses data Up to date } \\
\text { secara } \text { online }\end{array}$ & $\begin{array}{l}\text { Suporbility, dapat } \\
\text { digunakan hampir semua } \\
\text { sistem operasi. }\end{array}$ \\
\hline
\end{tabular}

\subsection{Functional Modeling}

Tahap kedua setelah setelah requirements ditentukan, adalah membuat function modeling. Dalam pengembangan aplikasi berbasis objek, terdapat dua diagram yang digunakan untuk menggambarkan interaksi ini, yaitu activity diagram dan use case diagram.

\subsubsection{Activity Diagram}

Activity diagram menggambarkan alur logika pekerjaan yang terjadi pada sistem tersebut. Activity diagram aplikasi CPC dapat dilihat pada Gambar 3.1.

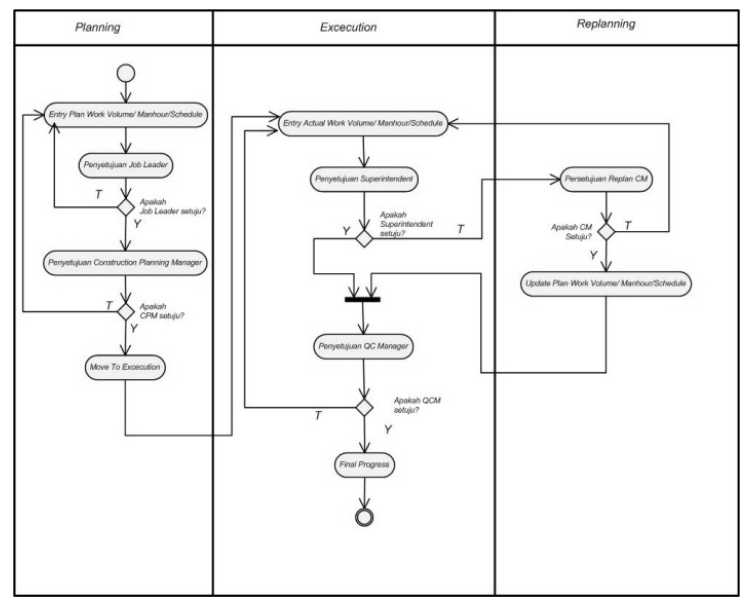

Gambar 3.1 Activity Diagram Aplikasi CPC

\subsubsection{Use Case Diagram}

Dalam use case diagram yang lebih diutamakan adalah mengenai apa yang akan diperbuat oleh sistem atau aplikasi, bukan mengenai bagaimana sistem atau aplikasi tersebut.

\section{a. Use Case Diagram Planning}

Use case diagram Planning menggambarkan tugas-tugas para aktor dalam tahap perencanaan. Aktor-aktor tersebut adalah sebagai berikut:

- Planner, bertugas memasukkan data planning.

- Job leader, bertugas meninjau data tersebut sebelum diserahkan kepada Construction Planning Manager (CPM).

- Construction Planning Manager, bertugas untuk menyetujui data tersebut dan memindahkan ke tahap eksekusi.

Gambar 3.2 merupakan gambar use case diagram planning 


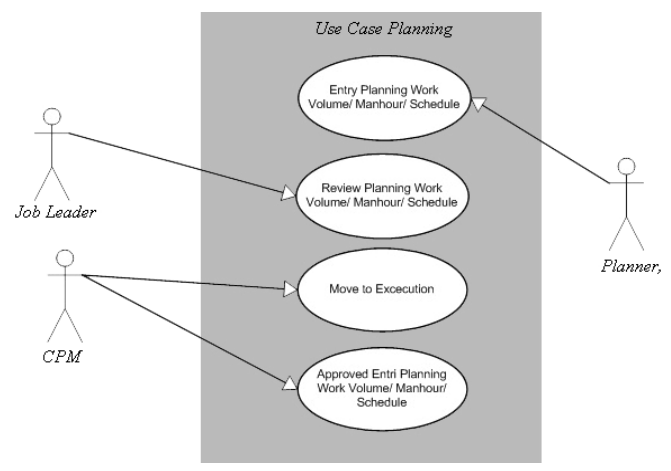

Gambar 3.2 Use Case Diagram Planning

b. Use Case Diagram Excecution

Use case ini menggambarkan tugas aktor-aktor dalam tahap eksekusi.aktor-aktor tersebut adalah sebagai berikut:

- Supervisor, bertugas menginput data-data

- Superintendent, bertugas untuk menyetujui data itu dan meneruskan ke Quality Control Manager (QC Manager).

- QC Manager, bertugas untuk menyetujui data tersebut dan menjadikanya sebagai Piping Discipline Progress.

Use case diagram excecution dapat dilihat pada Gambar 3.3.

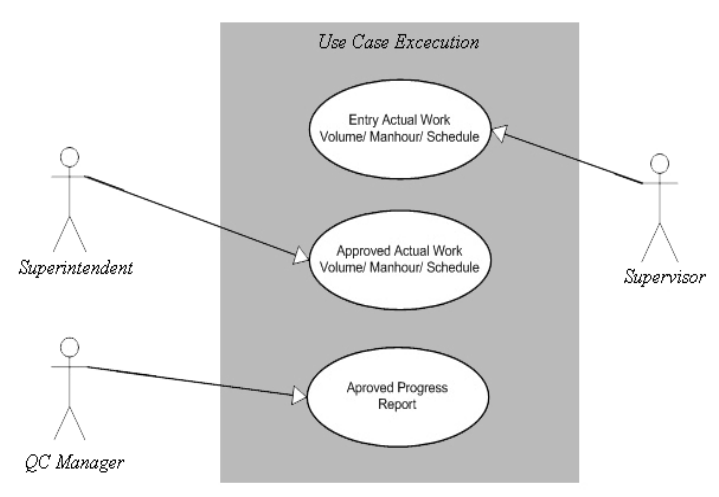

Gambar 3.3 Use Case Diagram Excecution

\section{c. Use Case Diagram Replanning}

Use Case Diagram Replanning menjelaskan kegiatan aktor-aktornya dalam tahap perencanaan ulang (replaning). Perencanaan ulang dilakukan apabila data Planning dan data aktual terlalu jauh perbedaanya. Dalam melakukan perencanaan ulang, harus mendapat persetujuan dari Construction Manager terlebih dahulu. Untuk use case diagram replanning dapat dilihat pada Gambar 3.4.

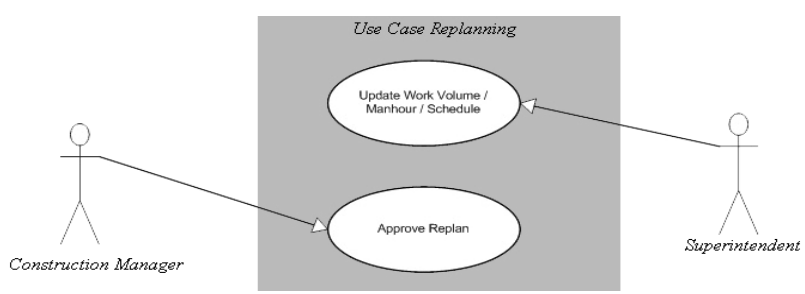

Gambar 3.4 Use Case Diagram Replanning

\subsection{Structural Modeling}

Structural modeling atau dalam bahasa Indonesia disebut dengan pemodelan terstruktur, merupakan model yang menggambarkan data yang mengalir melalui proses bisnis dalam suatu organisasi. Untuk pemodelanya menggunakan class diagram. class diagram pada aplikasi CPC dapat dilihat pada Gambar 3.5.

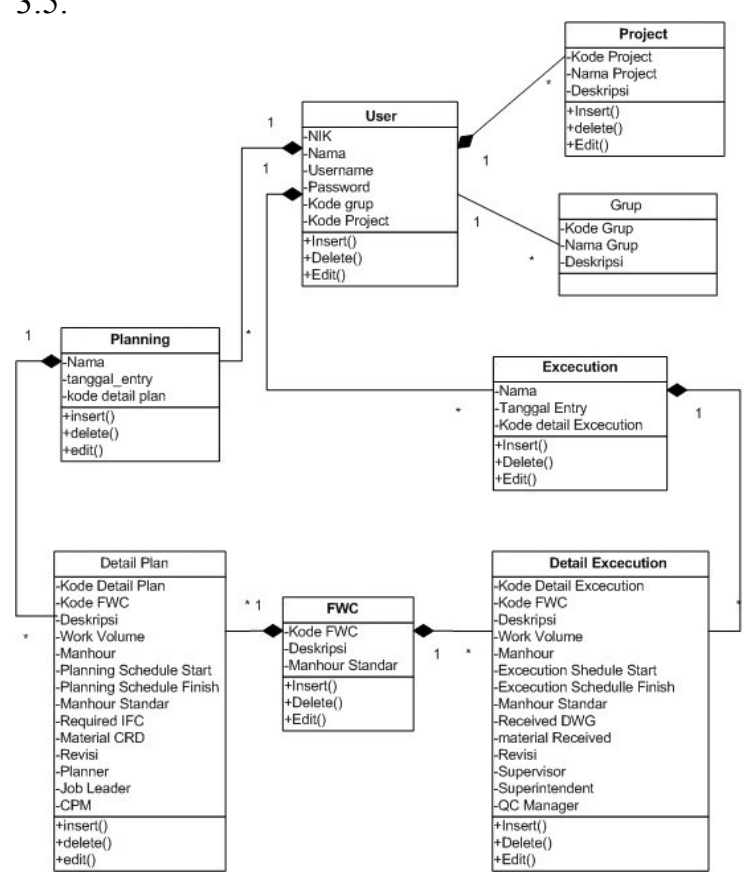

Gambar 3.5 Class Diagram Aplikasi CPC

\subsection{Behavioral Modeling}

Tahap analisis selanjutnya adalah behavioral modeling. Dalam behavioral dikenal adanya interaction diagram. Interaction diagram adalah model yang menggambarkan bagaimana sekelompok benda berkolaborasi dalam beberapa perilaku. Interaction diagram menggambarkan aspek dinamis dalam UML. Dalam interaction diagram ini, terdapat dua diagram yang berbeda, yaitu sequence diagram dan collaboration diagram.

\subsection{Sequence Diagram}

Sequence diagram pada CPC sendiri terbagi menjadi tiga bagian, yaitu sequence diagram planning, sequence diagram excecution dan sequence diagram replanning. 
a. Sequence Diagram Planning

Sequence diagram planning menjelaskan alur komunikasi antara objek objek yang mempresentasikan waktu pelaksanaan dalam tahap planning (perencanaan). Gambar 3.6 menunjukkan sequence diagram planning.



Gambar 3.6 Sequence Diagram Planning

b. Sequence Diagram Excecution

Aktor-aktor yang berperan dalam sequence diagram eksekusi ini adalah Supervisor, Superintendent, dan QC manager. Sequence diagram excecution dapat dilihat pada Gambar 3.7.

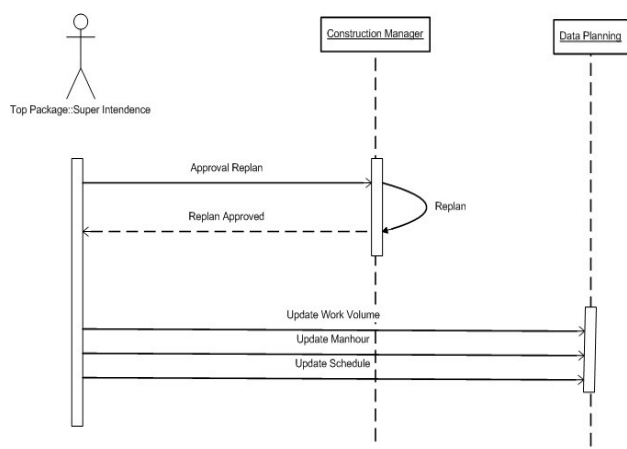

Gambar 3.7 Sequence Diagram Excecution

c. Sequence Diatgram Replanning

Sequence diagram yang terakhir adalah sequence diagram Replanning. Sequence ini menjelaskan alur komunikasi dalam tahap perencanaan ulang. Sequence diagram replanning dapat dilihat pada Gambar 3.8.

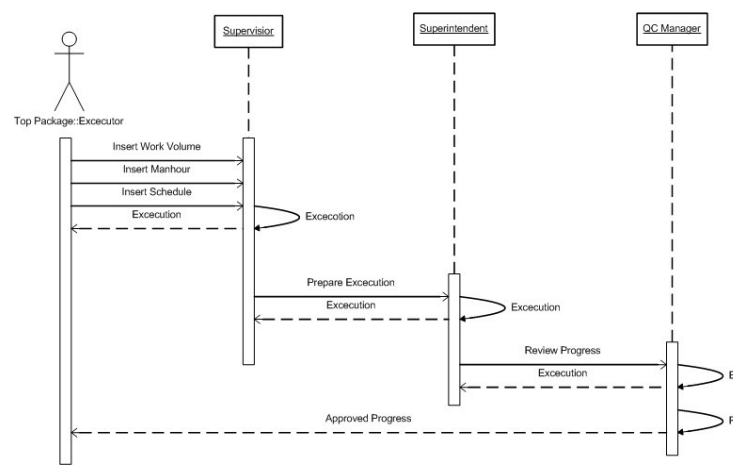

Gambar 3.8 Sequence Diagram Replanning

\subsection{Collaboration Diagam}

Collaboration Diagram aplikasi CPC menggambarkan interaksi dalam aplikasi ini. Collaboration diagram aplikasi CPC dapat dilihat pada Gambar 3.9.

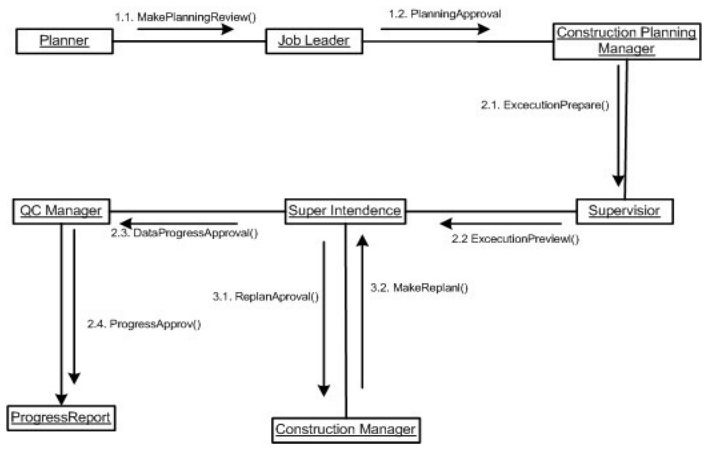

Gambar 3.9 Collaboration Diagram Aplikasi CPC

\subsection{Deployment Diagram}

Dalam Deployment diagram aplikasi CPC ini menunjukan hubungan antara node yang berbeda dalam jaringan. Juga mewakili komponen perangkat lunak dan bagaaimana mereka ditempatkan di atas arsitektur fisik dan infrastruktur aplikasi CPC. Gambar 3.10 adalah gambar dari deployment diagram aplikasi CPC.

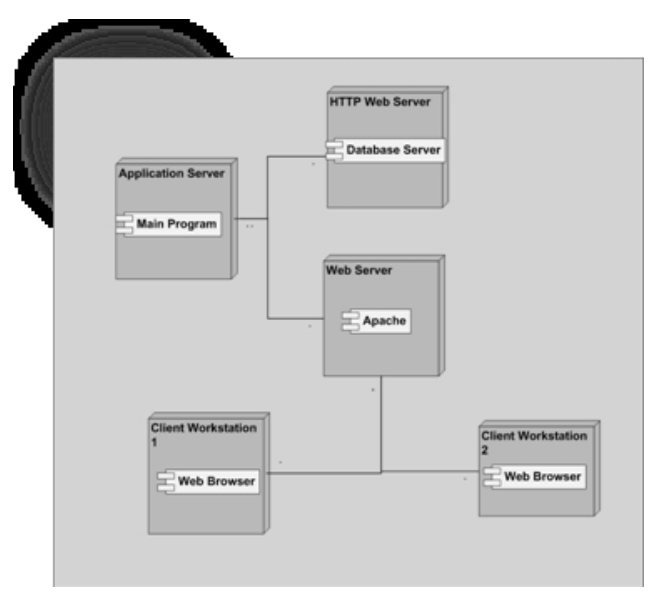

Gambar 3.10 Deployment Diagram CPC

3.6. Perancangan Tampilan

Halaman pada aplikasi CPC dibagi manjadi tiga kategori utama, yaitu halaman untuk Admin, halaman untuk Planner, dan halaman untuk Excecution.

\subsubsection{Perancangan Halaman Admin}

Halaman admin merupakan halaman untuk admin disiplin Piping. Dengan login sebagai administrator, pengguna mendapatkan hak akses penuh terhadap aplikasi ini, mulai dari insert-updatedelete pada semua data, admin juga dapat mengatur data pengguna berikut dengan username dan password para penggunanya dan mengecek historical data, yaitu 
rekaman aktivitas di dalam aplikasi CPC ini. Gambar 3.11 merupakan halaman login.

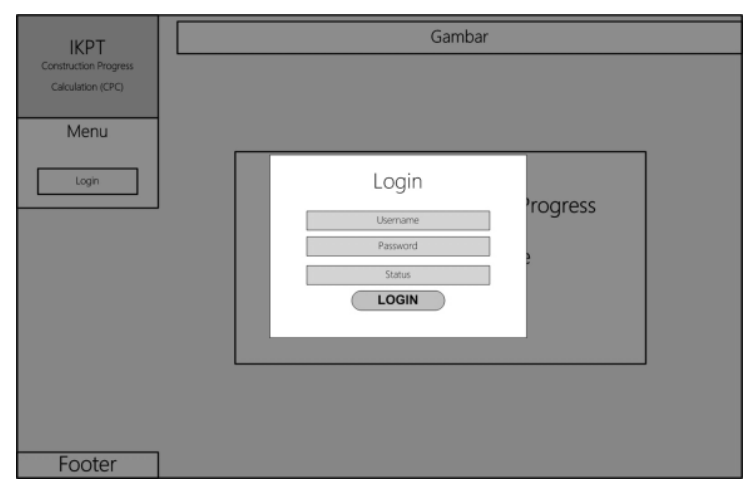

Gambar 3.11 Rancangan Halaman Login

\subsubsection{Perancangan Halaman Planning}

Halaman Planning, ditujukan untuk mereka yang berkepentingan terhadap data planning, yaitu untuk Planner sendiri yang bertugas mengisi data planning, untuk Job Leader, dan untuk Construction Planning Manager (CPM) Gambar 3.12 menunjukkan rancangan halaman Import Data Planning.

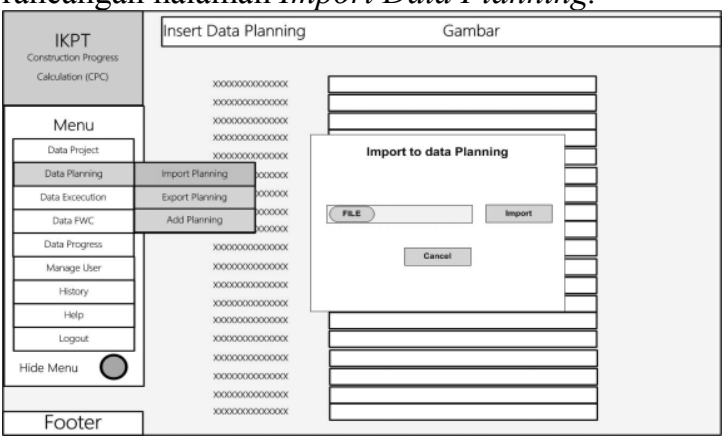

Gambar 3.12 Rancangan Import Data Planning

\subsubsection{Perancangan Halaman Excecution}

Halaman Eksekusi diperuntukan kepada pengguna yang mengolah data eksekusi yaitu untuk Supervisor yang bertugas menginput data-data eksekusi, untuk Superintendent dan QC Manager. Gambar 3.13 merupakan gambaran dari rancangan halaman Data Excecution.

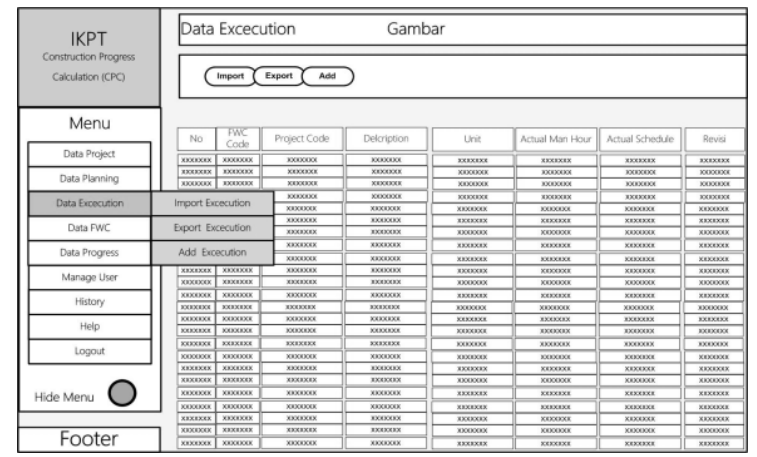

Gambar 3.13 Rancangan Halaman Data Excecution

\section{IMPLEMENTASI}

Implementasi aplikasi Construction Progress Calculation (CPC) yang sebelumnya telah dirancang terdiri dari Kebutuhan hardware dan software, implementasi database dan implementasi programnya.

\subsection{Kebutuhan Hardware dan Software}

Tabel 4.1 menjelaskan bagaimana hardware dan software yang akan dibutuhkan untuk implementasi aplikasi CPC ini.

Tabel 4.1 Kebutuhan Hardware dan Software

\begin{tabular}{|c|c|c|c|c|c|}
\hline No. & Specification & Standar Client & $\begin{array}{l}\text { Standar } \\
\text { Web Server }\end{array}$ & $\begin{array}{l}\text { Application } \\
\text { Server }\end{array}$ & $\begin{array}{l}\text { Database } \\
\text { Server }\end{array}$ \\
\hline 1 & \begin{tabular}{|l} 
Operating System \\
\end{tabular} & Windows & Linux & Windows & Linux \\
\hline 2 & Special Software & $\begin{array}{l}\text { - Chrome Browser } \\
\text { - Internet Explorer } \\
\text { - Ms. Excel }\end{array}$ & $\begin{array}{l}-P H P \\
\text { - Apache }\end{array}$ & $-P H P$ & $-M v S O L$ \\
\hline 3 & Hardware & $\begin{array}{l}-200 \text { GB Disk } \\
\text { Drive } \\
-2 \text { GB RAM } \\
\text { - Core i3 } \\
-17 \text { inci wide } \\
\text { monitor }\end{array}$ & $\begin{array}{l}-350 G b \\
\text { Disk } \\
\text { Dirive } \\
-2 \text { GB RAM } \\
\text { - Core i5 }\end{array}$ & $\begin{array}{l}-350 \text { Gb } \\
\text { Disk Dirive } \\
-2 \text { GB RAM } \\
\text { - Core is }\end{array}$ & $\begin{array}{l}\text { - } 500 \mathrm{~Gb} \\
\text { Disk Dirive } \\
\text { - Core i5 }\end{array}$ \\
\hline
\end{tabular}

\section{Implementasi Database}

Pembuatan database dalam aplikasi ini adalah menggunakan database MySQL dengan PHPMyAdmin sebagai alatnya. Gambar 4.1 merupakan gambar relasi database.



Gambar 4.1 Relasi Database CPC

\subsection{Impementasi Program}

Halaman awal saat pengguna membuka aplikasi ini adalah seperti yang terlihat pada Gambar 4.2. Halaman ini hanya terdapat logo dan satu menu, yaitu menu login. Untuk menggunakan aplikasi ini, pengguna harus login terlebih dahulu. 


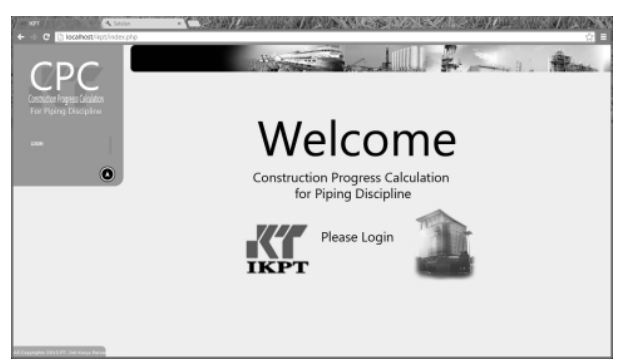

Gambar 4.2 Halaman Awal

\subsubsection{Impementasi Halaman Admin}

Dengan halaman ini, pengguna yang berstatus admin, akan memperolah semua hak akses mengenai aplikasi ini. Maka dari itu, di halaman admin terdapat semua fungsi dari aplikasi ini, fungsi-fungsi insertupdate-delete ada pada semua data. Gambar 4.3 merupakan gambar dari halaman Data Progress.



Gambar 4.3 Halaman Data Progress

\subsubsection{Impementasi Halaman Planning}

Halaman Planning diperuntukan bagi pengguna yang berkepentingan terhadap data planning. Ini dilakukan untuk menambah sistem pengamanan data, agar pengguna yang tidak berkepentingan, tidak dapat merubah bahkan menghapus data.

Menu import planning dapat digunakan untuk mengimpor data planning dari format .xls ke dalam database aplikasi. Gambar 4.4 merupakan gambaran dari import planning.

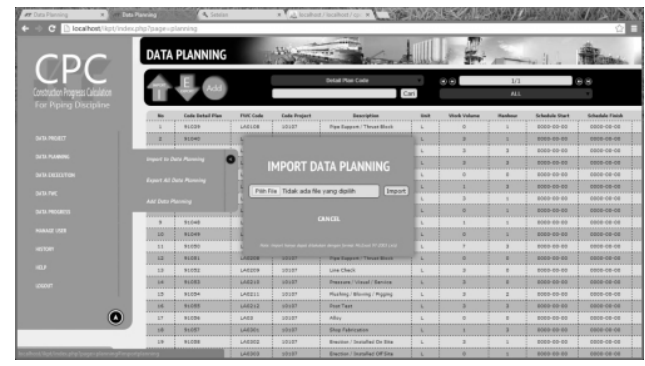

Gambar 4.4 Halaman Import Data Planning

\subsubsection{Impementasi Halaman Excecution}

Halaman Excecution diperuntukkan bagi yang berkepentingan dengan data Eksekusi, antara lain Supervisor, Superintendent dan $Q C$ Manager. Gambaran dari halaman Data Excecution dapat dilihat pada Gambar 4.5.

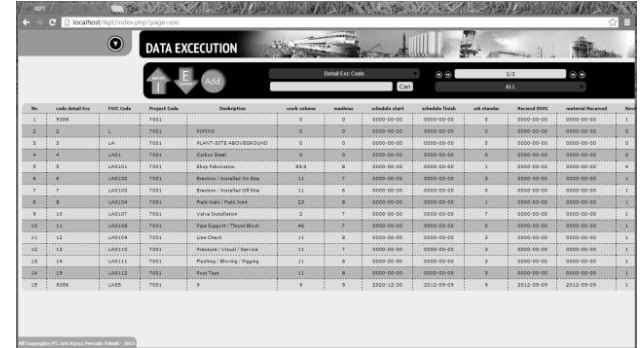

Gambar 4.5 Halaman Data Excecution

\section{SIMPULAN DAN SARAN}

Simpulan dan saran untuk aplikasi CPC adalah sebagai berikut.

\subsection{Simpulan}

Dari hasil analisi dan perancangan aplikasi Construction Progress Calculation (CPC) dapat diambil kesimpulan bahwa:

1) Aplikasi CPC dapat membantu tim eksekutor disiplin Piping untuk melakukan Planning dan reporting secara tepat dan terstruktur pada proyek yang sedang berjalan.

2) Perubahan rencana dalam sebuah proyek tidak dapat dihindari, maka dengan aplikasi CPC ini, disiplin Piping dapat dengan mudah mengontrol data jika terjadi perubahan rencana (replanning) tersebut.

\subsection{Saran}

Untuk memudahkan pengembangan aplikasi ini dikemudian hari, dapat digunakan suatu framework terutama yang sudah mendukung fasilitas MVC (Model View Controler), seperti Codeigniter agar pengembangan aplikasi menjadi lebih mudah walaupun bagi pengembang yang berbeda.

\section{DAFTAR PUSTAKA}

[1] Dennis, Alan, Barbara Haley Wixon, and David Tegarden (2009). System Analysis and Design With UML Version 2.0. . John Wiley \& Son, Inc, New Jersey

[2] Kadir, Abdul. (2009). Membuat aplikasi laporan menggunakan PHP. Penerbit Andi, Yogyakarta.

[3] McLeod, Raymond an Goerge P. Shell. (2008). Sistem Informasi Managemen. Salemba Empat, Jakarta.

[4] Soerjanto, Djoko. (2008). Pemrograman Web PHP. STEKOM, Semarang.

[5] Soetopo, Ariesto Hadi. (2002). Analisis dan Desain Berorientasi Objek. J \& J Learning, Yogyakarta.

[6] Sugiri, Haris Saputro. (2008). Pengelolaan Database MySQL dengan PHPMyAdmin. Graha Ilmu, Yogyakarta. 